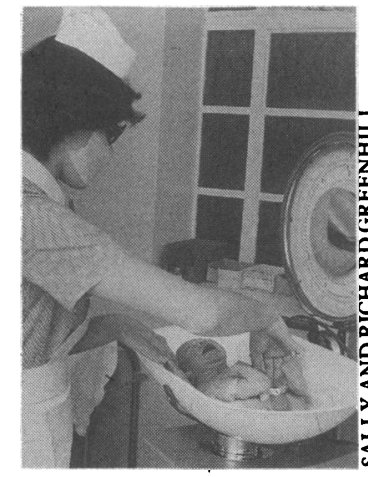

Converting 5 lb 8 oz to $2480 \mathrm{~g}$ or $2500 \mathrm{~g}$. It makes a difference, statistically of weights to exactly $2800 \mathrm{~g}$ this is consistent with the finding that there was less change in the proportion of low birthweight babies when this was used as the cut point. The change in recording suggests that a new look up table was introduced at some point for conversion of imperial to SI units (note that 1 ounce= 28 grams).

Mothers are usually familiar with, and prefer, pounds and ounces rather than grams, whereas official recording is undertaken in grams. If analogue scales are used dual reading of weight may be difficult, and the use of a look up table for conversion to SI units may offer a ready solution. If weight is rounded twice, first in ounces and then with a look up table when converting to grams, inaccuracies of up to almost $30 \mathrm{~g}$ may occur regularly.

Digital readout scales incorporating a printout and memory function may offer a solution but may not be an expense considered worthwhile by maternity units on clinical grounds. Until such devices are standard, rigorous adoption of SI units with regard to birth weight may require further encouragement within some maternity units.

Thanks are due to Miss Morley, director of midwifery, Queen Elizabeth Hospital, Gateshead, and Mr A McNay, statistician, Northern Health Region, for help with information.

1 World Health Organisation. Manual of International Statistical Classification of Diseases, Injuries and Causes of Death. Vol 1. Geneva: WHO, 1977.

2 Barell V, Wax Y, Ruder A. Analysis of geographic differentials in infant mortality rates. Am $\mathcal{F}$ Epidemiol 1988;128:218-30.

3 Townsend P, Phillimore P, Beattie A. Health and deprivation inequality and the north. Beckenham: Croom Helm, 1988.

\title{
An unusual case of neuropathic ulceration
}

\section{Keith Tayton}

The case described is of severe ulceration of the soles of both feet as a result of a transient but total anaesthesia in both legs.

\section{Case report}

A 58 year old man from a mining village in Gwent travelled to Yorkshire to attend a rugby match in the autumn of 1985. After the game he adjourned to a series of local taverns. By closing time he found himself many whiskies and over 12 pints of beer in credit, but he was 250 miles from home and had no money. Being, by now, a man of some spirit, he resolved to walk back to Gwent and purposefully headed south. Before he had gone far, his feet began to feel very sore owing to loosening of his shoes. To him there seemed only one solution, so he removed the offending shoes and threw them over a nearby hedge before continuing his journey. He tramped on, taking short cuts over walls and fences, sustaining a moderately severe head injury at one stage. Many miles later, near Barnsley, he flagged down a taxi and fell into the back seat, asking to be taken home.

About four hours later the patient's wife was summoned from her bed and presented with a taxi bill

Royal Gwent Hospital, Newport, Gwent NP9 2UB Keith Tayton, consultant orthopaedic surgeon

BMF 1992;305:1577 showed full thickness skin loss; exposed tendons were beginning to granulate over for $£ 115$. There was an initial danger of the patient spending the remainder of the weekend in his garden shed, but when this crisis had passed he retired to bed. Several hours later he appeared in the accident and emergency department in great pain and with severely ulcerated feet.

The left foot had full thickness skin loss under the second and third metatarsal heads and a partial thickness skin loss under the fourth and fifth metatarsal heads, under the tip of the big toe, and under the heel. The right foot had a severely contaminated wound under the second and third metatarsal heads. It consisted of a full thickness loss of the skin and subcutaneous fat, with exposure of the flexor tendons of the second and third toes. Partial thickness skin loss was also present under the first, fourth, and fifth metatarsal heads, under the tip of the big toe, and under the heel (figure).

All wounds underwent debridement and were cleaned and dressed. They healed without important complications over six weeks. No evidence of peripheal neuropathy could be found.

\section{Comment}

Well over half of the world's people always walk barefoot, but although terrain can vary considerably, severe ulceration of the foot is not often seen. It is well known that when long distance walking is undertaken by the uninitiated then blistering of the skin will develop, especially if shoes are worn. The extent of this blistering is limited usually by the severe pain experienced by the sufferers at the time.

Anaesthetic feet due to peripheral neuropathies are common and may present with ulceration much more severe than in this patient. This case is unusual, however, in that the anaesthesia was transient and almost total. Although the alcohol consumption was so great that its effect lasted for several hours, motor power and a reasonable amount of coordination were retained to such a degree that the patient was able to walk right through the soles of his feet and expose the flexor tendons to two of his toes.

As a result of this experience both the author and the patient would strongly recommend that before the results of any sporting fixture are celebrated, both shoes should be well fitting and firmly attached to the

Four days after admission to hospital the sole of the right foot still feet. 